\title{
FRAGMENTOS SOBRE A OBRA THE FORCE OF LAW DE FREDERICK SCHAUER
}

\author{
FRAGMENTS ON FREDERICK SCHAUER'S BOOK THE FORCE OF LAW
}

Felipe Labruna ${ }^{1}$

RESUMO: Em 2015 o jurista norte-americano Frederick Schauer publicou a obra The Force of Law, cujo teor não omite, desde o princípio de seu texto, que seu anseio ao escrevê-lo era opor-se à concepção proposta pelo estudioso inglês Herbert L. A. Hart no livro The Concept of Law, lançado em 2012, de que a natureza do Direito não abrange o componente coercitivo. Em The Force of Law é exposto que a coerção é o único componente do Direito usado até mesmo pelas democracias mais desenvolvidas a fim de que se garanta o cumprimento de seus próprios atos normativos. Entretanto, de acordo com o raciocínio perpetrado na obra, é um fato empírico que os indivíduos muito raramente obedecem à lei meramente por deferência à sua autoridade. O presente artigo se propõe a apresentar considerações sobre o livro, tomando como referência não apenas seu texto, mas publicações científicas relacionadas.

Palavras- chave: Coerção. Força. Frederick Schauer. Herbert Hart. The Force of Law.

ABSTRACT: In 2015, the north american jurist Frederick Schauer published The Force of Law, whose content does not omit, since the beginning of his text, that his desire to write it was to oppose the conception proposed by the english scholar Herbert L.A. Hart in book The Concept of Law, released in 2012, that the nature of law does not include the coercive component. In The Force of Law it is exposed that coercion is the only component of law used even by the most developed democracies in order to guarantee the fulfillment of their own normative acts. However, according to the reasoning perpetrated in the work, it is an empirical fact that individuals very rarely obey the law merely out of deference to its authority. This article proposes to present considerations about the book, taking as reference not only its text, but related scientific publications.

Keywords: coercion. force. Frederick Schauer. Herbert Hart. The Force of Law.

\footnotetext{
${ }^{1}$ Mestrando e graduado em Direito pela Pontifícia Universidade Católica de São Paulo. Especialista em Ciência Política pela Fundação Escola de Sociologia e Política de São Paulo e em Direito Processual Civil pela Escola Paulista da Magistratura. Oficial da Reserva do Exército Brasileiro pelo Centro de Preparação de Oficiais da Reserva de São Paulo. Diretor eleito da Associação de Pós-Graduandos da PUC-SP. Assessor no Tribunal de Justiça do Estado de São Paulo. E-mail: fe.labruna@gmail.com.
} 


\section{INTRODUÇÃO}

Posteriormente à publicação das obras Playing by the Rules em 1991 e Thinking Like a Lawyer em 2009, o jurista norte-americano Frederick Schauer nos prestigiou, na primeira metade de 2015, com o livro chamado The Force of Law. Em um primeiro momento, a locução do título pode fazer com que o leitor vislumbre uma interação com textos mais famigerados pelos estudiosos do Direito no Brasil, como Força de Lei de Jacques Derrida ou Estado de Exceção de Giorgio Agamben. Porém o tema abordado por Schauer é deveras diferente.

Frederick Schauer não omite, desde o início de seu livro, que sua intenção ao produzi-lo era contrapor o conceito proposto por Herbert L. A. Hart, em The Concept of Law do ano de 2012, de que a essência do Direito não abrange o componente coercitivo. Em outros termos, o anseio de Schauer é emergir a indagação da fundação da força nos ordenamentos jurídicos ou reaver a análise da coerção, há muito recusada pela Teoria do

Direito com o legado de Hart. Como resultado, Schauer igualmente compromete-se a questionar os modelos da atual Teoria do Direito, por motivos que se tornam compreensíveis no decorrer da leitura do livro (PUGLIESE; FORTES, 2015).

The Force of Law é de certa forma um livro sucinto, possui linguagem clara, pode ser lido por aqueles que não são especialistas e é repleto de exemplificações figuradas. Mesmo nos momentos em que é tratado sobre estudos empíricos realizados, há a presença de figuras bem-humoradas, o que contribui muito para que a leitura não se torne enfadonha. Ele possui onze capítulos e apresenta um paradigma interdisciplinar. Schauer se pauta não somente em argumentações filosóficas, mas também se escora em estudos e pesquisas empíricas derivadas das ciências da Sociologia, da Economia e da Psicologia Cognitiva.

Após o primeiro capítulo (Introdução), o Capítulo 2 apresenta uma narrativa histórica da relevância dada à coerção no entendimento da lei e esclarece as teorias de Jeremy Bentham e John Austin que, com certas diferenças, sopesavam a coerção central para o conceito de lei e para o discernimento entre instituições jurídicas e demais normas. No capítulo seguinte, o autor contrapõe as justificativas essencialistas da natureza do 
Direito. Já no Capítulo 4, Schauer analisa o puzzled man, que podemos chamar de "homem complexo", ou seja, um indivíduo que apenas cumpre a lei pelo simples fato de ela ser lei. $\mathrm{Na}$ ocasião também é apreciada a chamada falsa dicotomia entre a ação incentivada pela lei e a atitude motivada por anseios particulares. Já os Capítulos 5 e 6 são mais baseados pelo empirismo e é investigada pelo autor a quantidade de cidadãos e funcionários legais que cumprem os comandos legais somente por serem leis.

A partir do Capítulo 7, o livro passa a ter uma reflexão mais geral a respeito da função que a coerção possui nas atividades exercidas pelos sistemas jurídicos e sobre a distinção das instituições jurídicas perante as instituições normativas. No Capítulo 8, a intenção do livro é distinguir as diferentes espécies de incentivos que o comando normativo pode dar aos seus teores. Já no capítulo a seguir são dadas as definições dos conceitos centrais da obra: a coerção, a sanção e a compulsão. Embora esteja situado ao final do livro, este capítulo é extremamente importante para a boa compreensão do seu teor.

No Capítulo Io são feitas considerações sobre as similitudes e distinções entre a lei e as normas sociais, além de abordar de que forma a legislação pode delinear e enrijecer as normas sociais utilizando-se da coerção. Também é tratado sobre como as normas sociais podem ocasionar consonância com a coleção legislativa. Finalmente, no Capítulo II, o autor expõe alguns critérios que podem auxiliar o leitor a distinguir o Direito das demais instituições normativas. Como era de se esperar, a figura da coerção está incluída nestes critérios (MIOTTO, 2015).

\section{CONSIDERAÇÕES SOBRE A OBRA}

O livro The Force of Law aborda três questões importantes relacionadas à natureza da força através da qual a lei é capaz de moldar a sociedade. À medida que Schauer formula essa questão, a natureza da força, que é seu objeto de estudo, vem da capacidade da lei de influenciar o comportamento de indivíduos. É observado que nosso principal interesse na lei e nos sistemas jurídicos está em sua capacidade de moldar e influenciar o comportamento dos indivíduos. Dentro dessa estrutura de definição, são abordadas três 
preocupações. A primeira é a relevância de estudos jurídicos sobre porque as pessoas obedecem às leis. A segunda é a melhor conclusão que se pode obter ao revisar as conclusões de pesquisas empíricas em ciências sociais que abordam o tema. E a terceira é identificar os problemas e possibilidades da construção de um sistema jurídico baseado na coerção em conjunção com as normas sociais.

O primeiro argumento é muito razoável: a força é fundamental para a lei. Portanto, devemos procurar local no design institucional para determinar quando e como usar melhor a coerção para motivar a conformidade. Através do segundo argumento, Schauer argumenta que o papel das motivações independentes de sanções é exagerado. Seu argumento é baseado em uma apreciação exaustiva da literatura das Ciências Sociais para chegar a conclusões contrárias àquelas aceitas por cientistas sociais. Finalmente, a própria hipótese inicial de Schauer é relativizada no capítulo final quando afirma que as motivações não baseadas em sanções contidas em normas sociais emergem como ponto central para sua visão integrada da força da lei (TYLER, 20I6).

De forma não complementar e até pouco elogiosa à visão outrora consolidada por Herbert Hart, Frederick Schauer apresentou a figura do "indivíduo moral", quer seja, uma pessoa que atua por motivos diferentes de seus próprios anseios, mas que não necessita de motivações, prescrições ou comandos legais que a leve a fazer algo de determinada maneira. Faz-se necessário então pontuar exatamente como este personagem está relacionado e quais abordagens básicas ele representa. Isto porque Hart já havia retratado o sujeito "intrigado" ou "ignorante" com a finalidade de enfatizar a relevância do que chamou de "ponto de vista interno" daqueles que aceitam a normatividade de uma determinada regra em oposição ao ponto de vista externo.

Segundo a visão de Hart, há aqueles que rejeitam as regras de um determinado grupo e só se preocupam com elas quando e porque eles julgam que consequências desagradáveis seguirão sua violação normativa. Em outras palavras, de acordo com Hart, o homem "intrigado" segue o Direito por princípio, enquanto um suposto "homem mau" só obedeceria à lei por causa da ameaça de sanções. No entanto, Schauer procurou mostrar que a normatividade da lei tende a ofuscar que as pessoas podem, até mesmo em grande 
medida, agir com base em princípios morais ou, ao menos, independentemente das diretivas legais: as pessoas na verdade podem ser e agir como "pessoas morais". Aceitar isso, no entanto, significa aceitar a falta de uma característica que permite isolar o ímpeto para seguir a lei nas situações em que as exigências legais e morais estivessem alinhadas (BEZEMEK, 2016).

Para Schauer, a coerção é relativamente responsável por exercer uma "função de liquidação" no seio da lei: em outras palavras, solucionar problemáticas práticas, em que pese termos nossas dicotomias de ordem moral ou política. A legislação exerce esse encargo ao conceder, entre outras coisas, subsídios coercitivos para que os indivíduos e funcionários se privem de seus julgamentos pessoais e tornem-se adeptos da resolução sugerida pela lei (MIOTTO, 2015).

Há numerosos motivos para diferenciar a lei em si do ordenamento jurídico, mas um dos pretextos mais relevantes é que os tomadores de decisão jurídicos, ou seja, os magistrados, são evidentemente componentes do organograma legal, porém se utilizam de outros componentes que não são em si mesmos legais ou de Direito (como por exemplo as proposições gramaticais ou a semântica de brocardos ou então valores não técnicos da matemática). O quanto que os julgadores e demais personagens legais ou jurídicos utilizam para desembocarem em suas decisões para serem entendidas como Direito é deveras contraditado. Neste sentido, Hans Kelsen (1967) em sua obra Teoria Pura do Direito perseverou que "cada ato de aplicação da lei é apenas parcialmente determinada pela própria lei". ${ }^{2}$

Seria até possível dizer que o Direito é uma criação exclusiva do Estado-Nação e que nesse sentido os conjuntos de normas das demais organizações também são direitos, mas somente de uma forma figurada e não literal. Quem pensava dessa forma era o sociólogo alemão Max Weber, dizendo que o poder político é sempre poder coercitivo ancorado na utilização de penas e corretivos pelo Governo, afinal somente este tem legitimidade e autonomia para utilizar a força a fim de que sejam cumpridas as leis. Porém, para Schauer, a compreensão do Direito por Weber é exclusivamente sociológica e por esta

\footnotetext{
${ }^{2}$ KELSEN, Hans. Pure Theory of Law, $2^{\underline{a}}$ ed. Berkeley: University of California Press, 1967. Apud.
} SCHAUER, Frederick. The Force of Law. Massachusetts: Harvard University Press, 2015. 
razão nesta conjunção é deficitária, porque ela busca definir e limitar o que é e o que não é Direito, de dada maneira marginalizando o Direito que não é oriundo do poder estatal.

Tratando a respeito da distinção entre o que é Direito e o que não é, é possível que não haja delimitação entre aquilo que é correto e o que não é, mas isso não quer dizer que não exista diferença. É por esta razão que neste tópico a conceituação weberiana de Direito é diminuta. Entretanto, não é necessário que essa distinção se refira a uma única dimensão, afinal o Direito pode vir a ser distinguido em virtude de seus procedimentos, suas técnicas, suas fontes e sua estrutura social. Contudo, o Direito também pode ser singularizado pelo seu apelo à força (SCHAUER, 2015).

Segundo Schauer, estabelecer uma definição marginalizando tudo aquilo que não lhe é comum desagua no esgotamento da própria definição. Deste modo, afirmar que a coerção não compõe a definição de Direito é como ignorar o atributo de voar dos pássaros, meramente porque os pinguins não são hábeis a voar. Agir desta maneira simboliza desprezar uma característica manifestamente distintiva de uma definição em razão de ela não estar inserida em uma situação periférica.

Também se arrazoa que a coerção é o único componente do Direito usado até mesmo pelas democracias mais desenvolvidas a fim de que se garanta o cumprimento de seus próprios atos normativos. Manifestamente, a coerção também é um dos parcos componentes contidos nos ordenamentos mais totalitários - que não são elogiados, mas nem por isso deixam de ser observados por Schauer para expor suas perspectivas. Este panorama conduz o autor a sinalizar para a ubiquação da coerção. Para Schauer, é o componente coercitivo, excetuando-se os sistemas desenvolvidos somente em teoria, que diferencia o Direito das demais sistematizações normativas e de outros expedientes de estruturação social. Neste momento cumpre expor o anseio secundário da obra, que era o de contestar o método da Teoria do Direito: a sistemática de Schauer busca analisar a existência e descrever os organogramas jurídicos da realidade. É deste modo, na direção de renunciar a uma teoria distante da realidade, que se pode entender a missão metodológica oferecida (PUGLIESE; FORTES, 2015). 
Herbert Hart havia sustentado em The Concept of Law que a coerção não era um componente imprescindível à lei, mas uma coisa periférica e que a internalização dos atos normativos jurídicos é o bastante na maior parte das situações para assegurar a execução efetiva. Hart atacara a hipótese da coerção como um atributo indispensável (fundamental) do Direito e o alicerce de sua conceituação, estruturando então um pensamento jurídico de que era viável abalizar o Direito sem que se referisse ao seu componente coercitivo. Nesta direção, existia toda uma cadeia de atos normativos que concediam atribuições (prestar esclarecimentos, contrair matrimônio, deslocar-se para o exterior, etc.) que não eram dotadas, ao menos não em seu âmago, de uma alusão à utilização de força.

Da mesma forma, para Hart, uma cadeia de regulamentação e instruções de cunho administrativo, em última instância legal, não fazia menção à penalidades, havendo campos inteiros do Direito que operavam de maneira admissível, sem que fosse obrigatório o uso da força física. De outro prisma, foi debatido se outros institutos jurídicos, como é o caso das nulidades ou das indenizações, poderiam ser assemelhados às penalidades. Tal concepção de desnecessidade da coerção do Direito é, no momento, a mais propagada e tem sido a escolha referencial nas discussões travadas no seio da consciência contemporânea (MASSINI-CORREAS, 2018).

Em plena oposição ao defendido por Herbert Hart, para Schauer a participação de um poder dotado de coerção que não há como ser conjurado é o que frequentemente está por trás da locução "força de lei" e da mentalidade do cidadão ordinário que crê que a coerção é o feixe central do Direito pela própria noção de Direito. Como muitos outros atributos do Direito que vivenciamos, a coerção não é por si só o bastante. Porém a ubiquidade da coerção jurídica exibe o fato de que em muitos campos há propósitos/finalidades valiosos que não podem ser conquistados somente por meio da cooperação (SCHAUER, 2015).

Já havia sido exposto por Schauer antes da publicação de The Force of Law que no momento em que o filósofo da Grécia Antiga Sócrates insistira que a lei que o havia condenado injustamente ainda deveria ser cumprida e seguida, lançou naquele instante uma longa tradição de entendimento do cumprimento e obediência à lei apenas e tão 
somente porque é lei, como uma coisa com valoração moral e política autônoma (SCHAUER, 2010). Para Schauer, o motivo de obedecer à lei é muitas vezes a espada que, de uma maneira ou outra, é posicionada apontada no pescoço do indivíduo, o ameaçando na hipótese de descumprimento. Mas, quem sabe, apenas haja três possíveis motivos para a execução da lei: I) o melhor juízo moral pessoal, dada uma situação, pode vir a indicar o mesmo curso de ação apontado pela lei; 2) as preferências particulares levam a agir como a lei determina que se aja; 3) a lei punirá de alguma maneira se não se atuar conforme a lei determina que se atue (SCHAUER, 2015).

Ao ancorar a relevância da coerção na legislação, Schauer exibe um marco teórico diverso que igualmente está no cerne de The Force of Law. O fato de que a coerção há bastante tempo tem sido desprezada pelo conteúdo jurisprudencial analítico é uma projeção da concepção de que a função da jurisprudência é reconhecer a essência do Direito encarada como o agrupamento de atributos indispensáveis e suficientes que fazem com que a lei seja aquilo que ela é na totalidade possível de tempos e lugares. O estudioso defende então que esta interpelação à jurisprudência é equivocada. Uma elucidação da essência da lei deve se ater não em um grupo de características pretensamente indispensáveis, mas em quais é preponderante nos ordenamentos jurídicos da atualidade, em conformidade com os dados empíricos. Nesta direção, The Force of Law apresenta uma importante crítica à jurisprudência extensiva da atualidade e convencional.

Nos termos do que foi exposto na obra aqui retratada, a jurisprudência não deve ser estruturada como mero instrumento estático filosófico inclinado a uma abordagem conceitual que já é ultrapassada e defasada. A abordagem dos valores jurídicos deve ser tonificada com verificações empíricas e pautada pela pesquisa de atributos da Sociologia, da Psicologia, da Política e de aspectos econômicos do Direito. Nesta linha, a análise multidimensional auxiliaria a jurisprudência a melhor compreender o que de fato a lei é. Ademais, a inquirição da jurisprudência nestes termos poderia auxiliar em uma melhor estruturação das instituições jurídicas e na formulação de eficácia das orientações jurídicas (CANALE; TUZET, 2016). 
Os questionamentos que Schauer oferece para esclarecer e arrazoar coerção e penalidades são se as pessoas obedecem à lei e, se a obedecem, poderiam estar fazendo algo que apenas as faz parecer que estão obedecendo à lei. Nesse sentido, a lei lhe parece peculiar, afinal é distinta das demais estruturas normativas de ética e de ação correta. Para o autor, assim como o foi para Hans Kelsen e Norberto Bobbio, essa é a razão que torna o Direito ser diferenciado em relação às demais entidades de cunho social, político e cultural, afinal não apenas nos transmite o que fazer, mas nos acua com penalidades indesejadas.

Schauer aponta então uma diferenciação bem clara entre o comportamento que é adotado em conformidade com comandos e o comportamento que é apenas coerente com eles. Isso pode parecer demasiadamente controverso para aqueles que creem e agem sob o alicerce legal, porque sugestiona que é viável que a lei apenas indica as ações das pessoas e que elas poderiam agir de maneira diversa. Assim, a lei poderia vir a perder seu status social como um sistema distinto das demais estruturas morais e normativas. $\mathrm{Na}$ visão de Schauer, se estivéssemos interessados em Direito principalmente em razão do que ele pode vir a fazer por nós e se os comandos apenas orientassem a lei, então não conviria se importar com a lei (LADAVAC, 2016).

\section{CONSIDERAÇÕES FINAIS}

A obra a que trata este artigo traz em seu bojo a ideia de que, certamente, uma das ocorrências com o que uma justificativa ao Direito pode ser traçada é a da falibilidade do ser humano. É verdadeiro que o Direito exerce uma função relevante, entretanto tão atribuição não se restringe a acautelar indivíduos maus de tomarem atitudes ruins. Porém, de modo ainda mais significativo, o Direito remedeia que bons sujeitos executem aquilo que acreditam que é bom por boas razões.

Neste contexto, Frederick Schauer indica que há uma celeuma: o Direito atua dessa forma em parte porque habitamos um mundo heterogêneo em que o bem comum é constantemente perturbado por sujeitos que procuram a satisfação de seus interesses particulares e mais ainda, nos situamos em uma atmosfera em que determinadas coisas, que pessoas benevolentes com boas intenções acreditam que as estão fazendo, 
frequentemente não são tão boas quanto elas acham que são. Então, uma das atribuições do Direito é limitar até mesmo as crenças bem-intencionadas de pessoas altruístas.

É neste passo que o autor finaliza o livro dizendo que é justamente onde o começou. O Direito faz com que os indivíduos façam coisas que não desejam fazer. Deste modo, se há uma atribuição que o Direito pode executar melhor do que outras entidades e/ou ciências é a delimitação do comportamento. Porém, equiparar o Direito à coerção ou ao amedrontamento de punição ou algum outro "mal" é um enorme engano.

O Direito faz deveras mais coisas do que somente controlar, atemorizar, castigar e aplicar penalidades e nem sempre se faz necessária a coerção para que seja feito o que precisar ser executado. Entretanto, o fato de a coerção não ser absolutamente tudo em matéria de Direito e nem um atributo definidor dele, não significa também que não é nada de Direito ou um componente insignificante dele. Preterir a feição coercitiva do Direito às margens e bordas do interesse epistemológico seria uma ação degenerada. Desta feita, se ater ao aspecto coercitivo do Direito nos auxilia a compreender por qual razão e em que momento pode-se necessitar dele para fazer coisas que outras entidades políticas e modelos de organização social são incapazes.

\section{REFERÊNCIAS BIBLIOGRÁFICAS}

BEZEMEK, Cristoph. Bad for good: perspectives on Law and Force. In: BEZEMEK, Cristoph; LADAVAC, Nicoletta Bersier. The Force of Law reaffirmed: Frederick Schauer meets the critics. Nova York: Springer, 2016.

CANALE, Damiano; TUZET, Giovanni. Introduction to "Schauer and The Force of Law”. Ratio Juris, vol. 29, no 02. Nova Jersey: John Wiley \& Sons Ltd, 2016.

LADAVAC, Nicoletta. Coercion and sanctions as elements of normative systems. In: BEZEMEK, Cristoph; LADAVAC, Nicoletta Bersier. The Force of Law reaffirmed: Frederick Schauer meets the critics. Nova York: Springer, 2016.

MASSINI-CORREAS, Carlos I. Frederick Schauer. The Force of Law. Harvard University Press, Cambridge-Massachusetts/London, 2015. (Reseña). Persona y Derecho, $\mathrm{n}$ o 78. Pamplona: Universidad de Navarra, 2018 
MIOTTO, Lucas. Evaluating the Force of Law's force. Australian Journal of Legal Philosophy, vol. 40. Sidney: Australasian Society of Legal Philosophy, 2015.

PUGLIESE, William Soares; FORTES, Luiz Henrique Krassuski. The Force of Law, de Frederick Schauer. Revista da Faculdade de Direito - UFPR, vol. 6o, no o2. Curitiba: Universidade Federal do Paraná - UFPR, 2015.

SCHAUER, Frederick. The Force of Law. Massachusetts: Harvard University Press, 2015.

SCHAUER, Frederick. When and how (if at all) does law constrain official action? Georgia Law Review, vol. 45, no or. Athens: University of Georgia School of Law, 2010.

TYLER, Tom R. Understanding the Force of Law. Tulsa Law Review, vol. 5I, no 02 . Tulsa: University of Tulsa College of Law, 2016. 